\title{
Chondroitin sulfates in the developing rat hindbrain confine commissural projections of vestibular nuclear neurons
}

\author{
Jessica CF Kwok ${ }^{1,2}$, Ying-Lai Yuen ${ }^{1,3}$, Wai-Kit Lau ${ }^{3}$, Fu-Xing Zhang ${ }^{3,4}$, James W Fawcett ${ }^{2}$, Ying-Shing Chan ${ }^{3,5^{*}}$ and \\ Daisy KY Shum ${ }^{1,5^{*}}$
}

\begin{abstract}
Background: Establishing correct neuronal circuitry is crucial to proper function of the vertebrate nervous system. The abundance of chondroitin sulfate (CS) proteoglycans in embryonic neural environments suggests that matrix proteoglycans regulate axonal projections when fiber tracts have not yet formed. Among the early-born neurons, the vestibular nucleus (VN) neurons initiate commissural projections soon after generation at E12.5 and reach the contralateral target by E15.5 in the rat hindbrain. We therefore exploited 24-hour cultures (1 day in vitro (DIV)) of the rat embryos and chondroitinase $A B C$ treatment of the hindbrain matrix to reveal the role of CS moieties in axonal initiation and projection in the early hindbrain.
\end{abstract}

Results: Dil tracing from the VN at E12.5(+1 DIv showed contralaterally projecting fibers assuming fascicles that hardly reached the midline in the controls. In the enzyme-treated embryos, the majority of fibers were unfasciculated as they crossed the midline at $90^{\circ}$. At E13.5 $5_{(+1} \mathrm{DIV}$, the commissural projections formed fascicles and crossed the midline in the controls. Enzyme treatment apparently did not affect the pioneer axons that had advanced as thick fascicles normal to the midline and beyond, towards the contralateral VN. Later projections, however, traversed the enzyme-treated matrix as unfasciculated fibers, deviated from the normal course crossing the midline at various angles and extending beyond the contralateral VN. This suggests that CSs also limit the course of the later projections, which otherwise would be attracted to alternative targets.

Conclusions: CS moieties in the early hindbrain therefore control the course and fasciculation of axonal projections and the timing of axonal arrival at the target.

\section{Background}

The establishment of correct neuronal circuitry is crucial for proper function of the vertebrate nervous system. During development of the vertebrate hindbrain, the early but transient subdivision of the neuroepithelium into rhombomeres [1,2] lays the scaffold for the development of the complex nervous system. Studies have focused on identifying the intercellular signals and transcription factors involved in defining and maintaining the cell identity of individual rhombomeres [3-6].

\footnotetext{
* Correspondence: yschan@hku.hk; shumdkhk@hku.hk

'Department of Biochemistry, LKS Faculty of Medicine, The University of

Hong Kong, Sassoon Road, Hong Kong, China

${ }^{3}$ Department of Physiology, LKS Faculty of Medicine, The University of Hong

Kong, Sassoon Road, Hong Kong, China

Full list of author information is available at the end of the article
}

Less is known about the mechanisms that regulate cell movements important for the patterning and morphogenesis of the hindbrain.

The vestibular nucleus ( $\mathrm{VN})$ is generated as four main neuronal clusters, each spanning several rhombomeres but differing in the rostrocaudal span along the hindbrain [7-10]. Radiographic birth-dating indicated an orderly progression led by neurons of the lateral VN, then the superior $\mathrm{VN}$ and inferior $\mathrm{VN}$, and finally the medial $\mathrm{VN}$, with peaks respectively on embryonic day (E)12.5 to E14.5 in the rat [7]. Afferent projections from these nuclei to major vestibulo-motor-related targets were observable as early as E11.5 (mouse) and E12.5 (rat) [7-10]. Once the pioneer afferents have been initiated, the advancing growth cones navigate the 'local' environment for positional and directional cues in the 
determination of a path to their target. Little is known about molecules involved in the pathway navigation. Studies on other systems indicated involvement of the Eph receptor tyrosine kinases and their membranebound ligand, ephrins, in growth cone negotiation with rhombomere boundaries [11-13]. The chondroitin sulfate (CS) proteoglycans (CSPGs) are strategically located in the extracellular matrix of the developing brain to influence cell-matrix adhesion and neurite outgrowth. In the chick brain, expression of CS was found to peak at the rhombomeric stage of hindbrain development [14]. Despite reports of CSPGs in the developing brain, their role in fiber projections in early embryos when pioneer axons are negotiating the path to reach their targets remains largely unexplored.

In this study, we are the first to report live treatment of the hindbrain matrix of rat embryos (E12.5 to E14.5) with chondroitinase $\mathrm{ABC}\left(\mathrm{Ch}^{\mathrm{ABC}}\right)$ for 1 day in culture during which the course of commissural projections is perturbed by enzymatic depletion of CS moieties. Following the treatment, we employed the lipophilic dye DiI to track contralateral projections from the $\mathrm{VN}$ in fixed hindbrains. The consequent increases in projection distance and number of unfasciculated fibers as well as the deviated courses of unfasciculated fibers revealed that axon-restrictiveness of CS moieties in the early hindbrain matrix controls the timing and abundance of axons that end at the contralateral $\mathrm{VN}$ target.

\section{Materials and methods \\ Animal sources}

Pregnant Sprague Dawley rats (gestation day 12.5 to 14.5 ; $\mathrm{n} \geq 5$ for each stage) were provided by the Laboratory Animal Unit at The University of Hong Kong. All procedures were in strict accordance with the NIH Guide for the Care and Use of Laboratory Animals and approved by the Committee on the Use of Live Animals for Teaching and Research (The University of Hong Kong).

Pregnant rats were anaesthetized with sodium pentobarbital $(30 \mathrm{mg} / \mathrm{kg}$ ) and the abdomen dissected for embryo collection. After transfer of embryos to DMEM (Sigma, St. Louis, MO, USA), the pregnant rats were sacrificed with an overdose of sodium pentobarbital (60 $\mathrm{mg} / \mathrm{kg})$.

\section{Embryo culture and chondroitinase $A B C$ injection}

Whole embryo culture was performed as described by New [15]. The decidual tissue and Reichert's membrane were excised from the collected embryos, leaving the intact yolk sac behind. The yolk sac was opened with caution not to damage the yolk-sac vasculature. $\mathrm{Ch}^{\mathrm{ABC}}(1$ $\mu \mathrm{l}$ of $10 \mathrm{U} / \mathrm{ml}$; Proteus vulgaris, Seikagaku, Tokyo, Japan) was then injected into the fourth ventricle of the embryo. Fast Green (1:10,000 w/v; Sigma) was included in the
$\mathrm{Ch}^{\mathrm{ABC}}$ solution to aid visualization (Figure 1A,B). PBS and heat-inactivated $\mathrm{Ch}^{\mathrm{ABC}}$ were both used as controls. As the results for both controls were similar, only the results from PBS-treated embryos are shown. The embryos were maintained in culture in DMEM/F12 with $10 \%$ fetal calf serum (Gibco, Invitrogen Grand Island, $\mathrm{NY}$, USA), $100 \mathrm{U} / \mathrm{ml}$ of penicillin (Sigma) and $0.1 \mathrm{mg} / \mathrm{ml}$ of streptomycin (Sigma) for 24 hours at $37^{\circ} \mathrm{C}$ with shaking. At the end of the culture period, the embryos were examined for heartbeat and expected increase in size. Only viable embryos were further processed for DiI labeling (Molecular Probes, Invitrogen, Eugene, OR, USA).

\section{Dil labeling}

Hindbrains were dissected out from viable embryos recovered from the culture. Cutting along the dorsal midline allowed flat-mounting of the hindbrain with the ventricular side facing up (Figure $1 C, D$ ). The hindbrains were kept thinly overlaid with $4 \%$ paraformaldehyde for 24 hours. The lipophilic indocarbocyanine dye DiI (1 $\mathrm{mg} / \mathrm{ml}$ in DMSO; Molecular Probes, Invitrogen) was applied into the floor of the fourth ventricle to target VN neurons at the rhombomere 4/5 border. To confirm the location of VN neurons, another lipophilic dye, NeuroVue Maroon (Polysciences, Warrington, PA, USA) [16] was applied to the VIIIth cranial nerve root such that the labeled afferent to the VN could be visualized (Figure 1F). After labeling, the hindbrain flat-mounts were kept in $4 \%$ paraformaldehyde (Sigma) at $37^{\circ} \mathrm{C}$ in the dark for 3 days to allow for the diffusion of the dye along fiber tracts. The hindbrains were mounted on glass slides with $1 \mathrm{X}$ PBS for observation. Images of labeled cells and fiber outgrowths were captured under a fluorescence microscope Axiophot 2 (Carl Zeiss, Thornwood, NY, USA) or MRC-1024 Laser Scanning Confocal Imaging System (Bio-Rad, Hercules, CA, USA). Montages of the images were constructed.

\section{Immunohistochemistry}

Hindbrains were fixed with $4 \%$ paraformaldehyde in $1 \times$ PBS at $4^{\circ} \mathrm{C}$ overnight followed by immersion in $30 \%$ sucrose solution for at least 24 hours at $4^{\circ} \mathrm{C}$ for cryoprotection. Transverse sections $(14 \mu \mathrm{m})$ were prepared with the cryostat and then incubated $\left(4^{\circ} \mathrm{C}\right.$ for 16 hours) with the monoclonal antibody CS-56 (1:250; IgM, Sigma) or one of the stub-sensitive antibodies 1B5, 2B6 (1:250; IgG, Seikagaku) or 3B3 (1:250; IgM, Seikagaku) in $1 \times$ PBS with $0.3 \%$ Triton-X and $3 \%$ normal goat serum. CS-56-stained sections were incubated with biotinylated goat anti-mouse IgM secondary antibody (1:500; Molecular Probes, Invitrogen) and then with Streptavidin-Alexa 488 (1:500; Molecular Probes, Invitrogen) for 1 hour at $24^{\circ} \mathrm{C}$. Those stained for the stub epitope were incubated with Alexa fluor 488-conjugated 

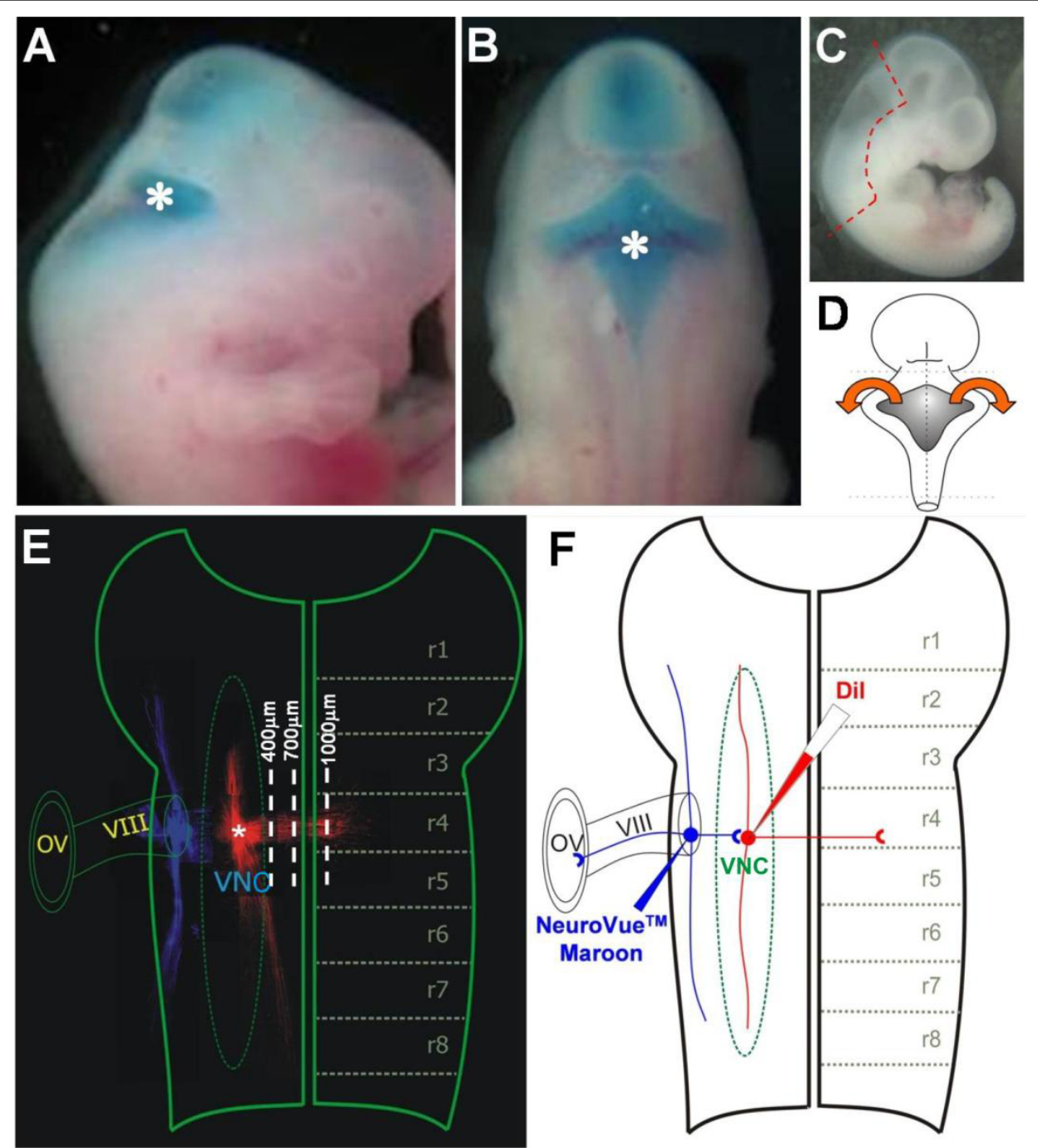

Figure 1 Preparation of the embryo. (A,B) Injection of $\mathrm{Ch}^{\mathrm{ABC}}$ into the fourth ventricle in the embryos was visualized by fast green included in the enzyme solution: (A) side view and (B) dorsal view of the embryos. The asterisk marks the position of the fourth ventricle. (C) The dashed red line outlines the hindbrain region to be dissected out from the embryo. (D) Schematic diagram showing cuts made in the dorsal neural tube to expose the ventricular surface of the hindbrain. (E) Flat-mounted hindbrain showing the Dil (red) and NeuroVue Maroon (blue) tracked fibers. Overlay of longitudinal gridlines (white dashed lines) assist fiber counting. The center of the dye injection (indicated by the asterisk) was designated as $0 \mu \mathrm{m}$. Gridlines of $100 \mu \mathrm{m}$ were drawn parallel to the floor plate. (F) Schematic diagram showing a flat-mounted hindbrain with the ventricular surface facing up. The dashed outline in green indicates the extent of the VN complex (VNC) in the hindbrain. The dotted lines in black indicate the rhombomere boundaries. Targeting of Dil (red) to the VN neurons was confirmed by afferents that were labeled by NeuroVue Maroon (blue) introduced into the VIIIth cranial nerve root and their termination on the Dil-labeled VN neurons. Abbreviations: OV, otic vesicle; r, rhombomere; VIII, VIIIth cranial nerve.

donkey anti-mouse IgG (1:500; Molecular Probes, Invitrogen). The sections were coverslipped and images observed under a Leica Leitz DMRD microscope were captured with a Nikon Digital Camera DMX1200.

\section{Quantification of Dil-labeled fibers}

Montage images from both PBS- $(\mathrm{n}>5)$ and $\mathrm{Ch}^{\mathrm{ABC}}$ treated hindbrains $(n>5)$ were assessed for number of contralaterally projecting fibers and their state of fasciculation. Fibers were considered unfasciculated when diameters were $\leq 5 \mu \mathrm{m}$ and fasciculated when diameters were $>5 \mu \mathrm{m}$. For fiber counting, a grid of longitudinal lines spaced at $100 \mu \mathrm{m}$ intervals was placed against the montage and the DiI-injection site was set as zero. Fasciculated and unfasciculated fibers that crossed each gridline were counted.

\section{Statistical analysis}

All data are expressed as means \pm standard deviation. Data resulting from $\mathrm{Ch}^{\mathrm{ABC}}$ treatment versus $\mathrm{PBS}$ 
controls were analyzed by the Mann-Whitney's U test with use of the computer software PRISM (GraphPad Software, Inc La Jolla, CA, USA \{). Statistical significance was accepted at $P<0.05$.

\section{Results}

Early embryos survive $\mathrm{Ch}^{\mathrm{ABC}}$ treatment of the hindbrain matrix

To determine if $\mathrm{Ch}^{\mathrm{ABC}}$ treatment via the fourth ventricle affected viability of the embryos in ex vivo culture, the embryos were rated as viable if heartbeat and growth in body size at the end of the 24-hour culture were comparable to those of similar stage embryos freshly harvested from the mother. Embryos that did not measure up to these criteria were excluded from the study. As shown for the viable embryo at E12.5 versus E12.5 (+ 1 DIV) (Figure 2B), growth in size was obvious. In all stages studied, the number of somites in viable embryos that survived $\mathrm{Ch}^{\mathrm{ABC}}$ treatment was the same as that in the PBS controls and that expected at the embryonic stage. Treatment with $\mathrm{Ch}^{\mathrm{ABC}}$ did not differ
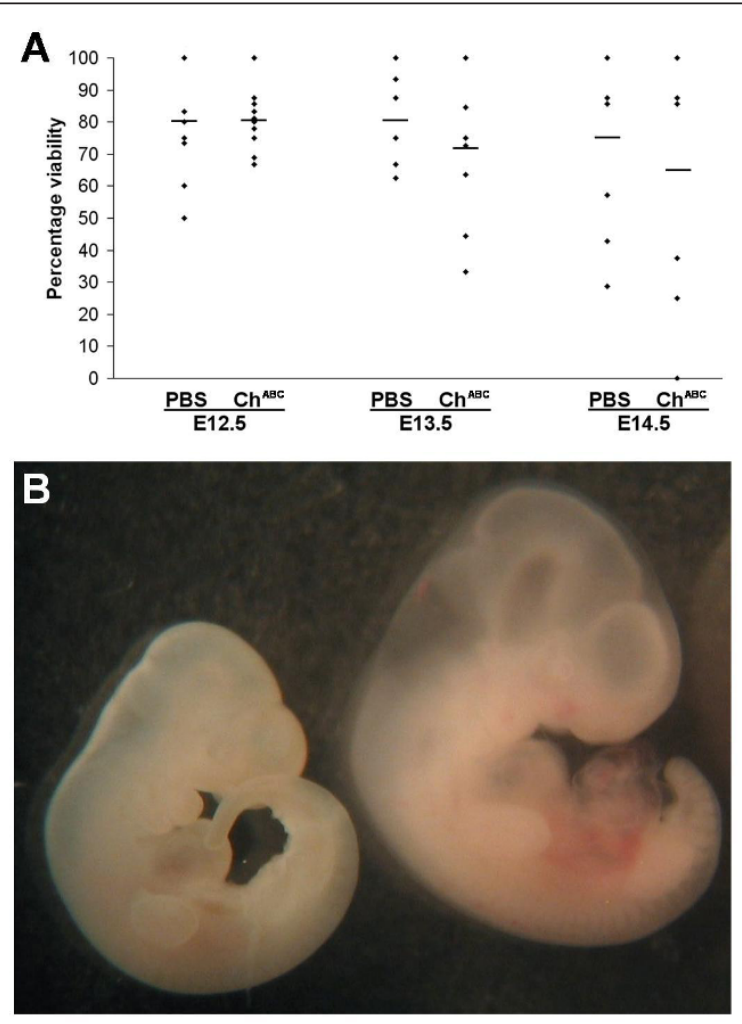

Figure 2 Viability of embryos in 24-hour culture with PBS/ $\mathrm{Ch}^{\mathrm{ABC}}$ delivered to the fourth ventricle. (A) Plot of percentage viability against the indicated stage and treatment. Each dot represents the percentage viability of the litter tested. The data were analyzed using the two-tailed Student's t-test. (B) E12.5 embryo (left) compared to an E12.5(+1 DIv) (right) litter mate, showing significant growth in size after 24 hours in culture. significantly from the PBS control in viability among embryos at E12.5 (+ 1 DIV), averaging $80 \pm 10 \%$ (Figure $2 \mathrm{~A})$. At E13.5 (+ 1 DIV), the viability dropped to $71 \pm 23 \%$ with $\mathrm{Ch}^{\mathrm{ABC}}$ treatment, significantly lower $(P<0.05)$ than the viability of $82 \pm 15 \%$ maintained by the PBS controls. At E14.5 (+1 DIV), viability dropped further to 65 $\pm 33 \%$ with $\mathrm{Ch}^{\mathrm{ABC}}$ treatment, not significantly different from the $75 \pm 29 \%$ of the PBS controls. Taken together, embryo culture at E14.5 $(+1$ DIV) is limiting to life, whereas at E13.5 (+1 DIV), CS-dependent life processes are compromised by depletion of $\mathrm{CS}$ in the hindbrain matrix, and at E12.5 (+1 DIV), these CS-dependent life processes have possibly not been fully differentiated, if at all.

\section{$\mathrm{Ch}^{\mathrm{ABC}}$ diffuses into the hindbrain matrix and acts to cleave the matrix CS}

If $\mathrm{Ch}^{\mathrm{ABC}}$ in the injection mix could digest the hindbrain matrix $\mathrm{CS}$, unsulfated $(\triangle \mathrm{Di}-0 \mathrm{~S})$, 4-sulfated $(\Delta \mathrm{Di}$ $4 S)$ or 6 -sulfated $(\Delta \mathrm{Di}-6 \mathrm{~S})$ stubs that remain with the matrix proteoglycans would be recognized by the monoclonal antibodies 1B5, $2 \mathrm{~B} 6$ and 3B3, respectively. Otherwise, the intact CS would stain positive with the monoclonal antibody CS56. As expected, the hindbrain matrix of PBS controls stained positive with CS56 (Figure $3 \mathrm{~A}, \mathrm{E}$ ) but showed no immunoreactivity with $2 \mathrm{~B} 6$ (Figure 3C,G) and likewise with $1 \mathrm{~B} 5$ and $3 \mathrm{~B} 3$ (results not shown). With $\mathrm{Ch}^{\mathrm{ABC}}$ treatment, the hindbrain matrix then lost immunoreactivity with CS56 (Figure 3B,F) and developed immunoreactivity with 2B6 (Figure $3 \mathrm{D}, \mathrm{H})$; signals for $1 \mathrm{~B} 5$ and $3 \mathrm{~B} 3$ were barely detectable (results not shown). The results therefore indicate that CS moieties of the hindbrain matrix were accessible to digestion by $\mathrm{Ch}^{\mathrm{ABC}}$ delivered into the fourth ventricle and that CS stubs exposed as a result of $\mathrm{Ch}^{\mathrm{ABC}}$ activity on the matrix CSPGs were essentially 4-sulfated.

In contrast, strong CS56-positive signal in the mesenchymal tissue bordering the neuroepithelial tissue of the hindbrain (Figure 3A,B) remained strongly CS56positive after $\mathrm{Ch}^{\mathrm{ABC}}$ treatment, apparently unperturbed or inaccessible by $\mathrm{Ch}^{\mathrm{ABC}}$ delivered into the fourth ventricle. Strong CS56-positive signals were also found along the ventricular surface of the hindbrain (PBS-treated; Figure 3A). Following $\mathrm{Ch}^{\mathrm{ABC}}$ treatment, weakening of these signals (Figure 3B) was accompanied by emergence of strong 2B6-positive signals (Figure 3D). These results indicate that despite proximity of $\mathrm{Ch}^{\mathrm{ABC}}$ to the ventricular zone, the enrichment of CSPGs and their involvement in cell/matrix interactions render the CS moieties incompletely accessible to $\mathrm{Ch}^{\mathrm{ABC}}$ activity. Taken together, $\mathrm{Ch}^{\mathrm{ABC}}$ delivered into the fourth ventricle adequately depleted CS moieties of the hindbrain matrix. 

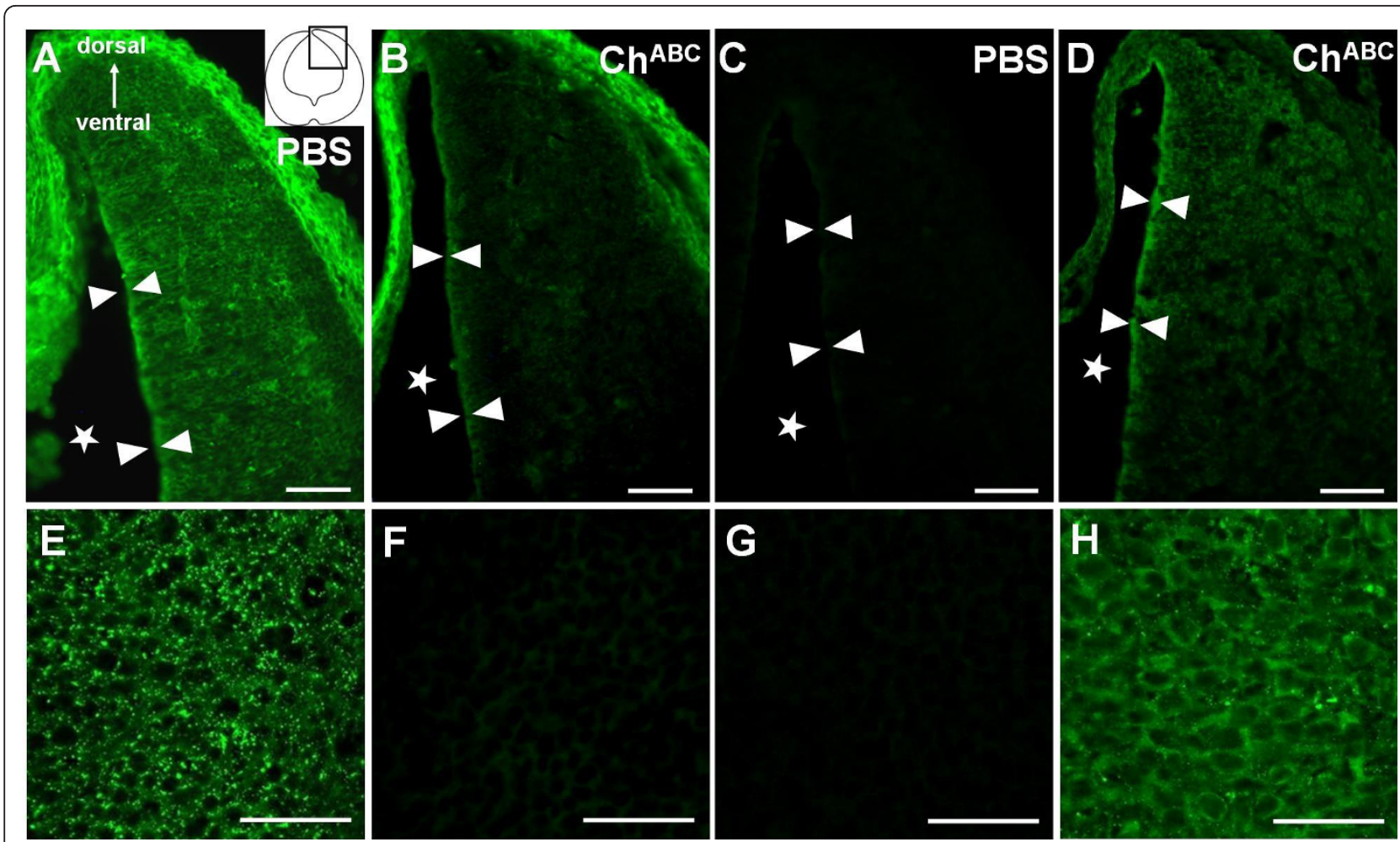

Figure 3 Immunoreactivity for CS epitopes in hindbrain sections of E13.5 (+1 $_{\text {DIV }}$ hindbrain sections. (A-H) Staining for the CS-56 epitope following control treatment with PBS (A,B,E,F) and the 2B6-stub epitope following $\mathrm{Ch}^{\mathrm{ABC}}$ treatment $(\mathrm{C}, \mathrm{D}, \mathrm{G}, \mathrm{H})$. Images correspond to the boxed region shown in the schematic diagram of the hindbrain section in (A). Zoomed-in views of the hindbrain matrix are shown below the corresponding images of the hindbrain sections. Asterisks indicate the region of the fourth ventricle; arrowheads indicate the outline of the ventricular surfaces of the hindbrain. Sections are $14 \mu \mathrm{m}$. Scale bars: $100 \mu \mathrm{m}$ (upper panels); $50 \mu \mathrm{m}$ (lower panels).

\section{Changes in commissural projections with depletion of matrix CS moieties}

Preliminary experiments that targeted DiI to the VN of E13.5 to 15.5 embryos provided confidence as to the location and depth of dye application into the floor of the fourth ventricle (Figures 4 and 5A). DiI-labeled fibers took a ventromedial course towards the floor plate as the growing end approached but had not reached the midline by E13.5 (Figure 5B). This was confirmed by attempts at retrograde labeling of $\mathrm{VN}$ neurons by DiI application at the floor plate - few, if any, VN neurons were so labeled in the E13.5 embryo (Figure 5 C,D). By application of NeuroVue Maroon to the VIIIth cranial nerve root in combination with DiI to the VN, we attempted to track NeuroVue Maroon-labeled afferents that terminate on DiI-labeled VN neuronal cell bodies or dendrites. Flat-mount of the hindbrain indicated NeuroVue Maroon-labeled afferents reaching DiIlabeled projections (Figure 1E,F). Whether the afferents terminate on dendritic projections of $\mathrm{VN}$ neurons or on long dendrites that extend into the VN complex from the reticular formation cannot be deciphered at E13.5. Although this attempt to characterize the VN neurons was inconclusive, targeting DiI to the $\mathrm{VN}$ indicated the possibility of mapping out the developing course of commissural projections from the VN.

The changes in commissural projections from the VN as a result of treatment with $\mathrm{Ch}^{\mathrm{ABC}}$ were then studied with DiI-tracking in respect of projection distance, number of DiI-tracked fibers, fasciculation of DiI-tracked fibers and projection direction. Among E12.5 (+1 DIV) embryos that had undergone control treatment with heat-inactivated $\mathrm{Ch}^{\mathrm{ABC}}$ or PBS, vestibular commissures appeared fasciculated and projected in a direction almost normal to the midline (Figure 6A). This was not different from projections found in E13.5 embryos that developed in utero. Given the high cost of commercial $\mathrm{Ch}^{\mathrm{ABC}}$, treatment of stage-matched embryos with PBS was considered an adequate control to test treatment with $\mathrm{Ch}^{\mathrm{ABC}}$. Results presented are representative of at least five independent experiments in which PBS control and $\mathrm{Ch}^{\mathrm{ABC}}$ treatments were performed on littermates. Montage images of the $\mathrm{VN}$ commissural projections in PBS- versus $\mathrm{Ch}^{\mathrm{ABC}}$-treated hindbrains are shown in Figure 6 and zoomed-in views of projections that crossed the midline are shown for E13.5 $5_{(+1}$ DIV) (Figure 7A,B) 

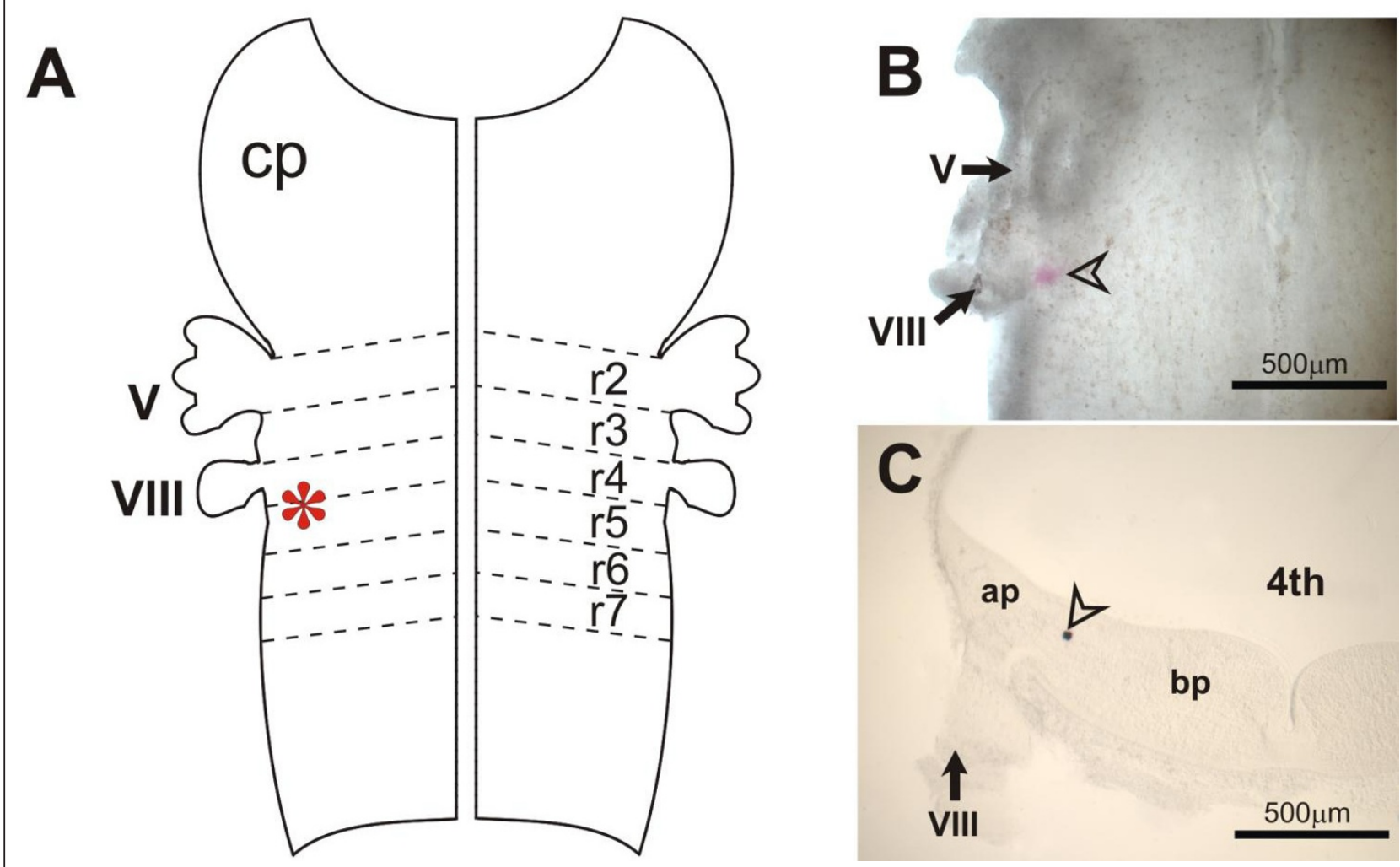

Figure 4 Preliminary experiments to decide landmarks for Dil application to the VN. (A) Schematic diagram showing a flat-mounted hindbrain with the ventricular surface facing up. Dil application was at a site close to the VIIlth cranial nerve root and along the rhombomere 4/ 5 border (indicated by the asterisk). (B) Brightfield image of a flat-mounted hindbrain (E13.5) after Dil/DMSO was injected at a site (arrowhead) close to the VIIIth cranial nerve root (VIII). (C) Transverse section of the hindbrain at the level of the VIIIth cranial nerve root (VIII) after Dil crystal was applied at a site (arrowhead) approximately $75 \mu \mathrm{m}$ from the floor of the fourth ventricle and in the alar plate. Abbreviations: 4th, fourth ventricle; ap, alar plate; bp, basal plate; $c p$, cerebellar primordium; $V$, Vth cranial nerve root; VIII, VIIIth cranial nerve root; $r 2$ to $r 7$, rhombomeres 2 to 7.

and E14.5 $5_{(+1}$ DIV) (Figure 7C,D). Corresponding histograms of the projections, fasciculated and unfasciculated, in the direction of the contralateral $\mathrm{VN}$ are shown in Figure 8.

\section{Projection direction}

Only projections toward the contralateral side were plotted in the histograms. For PBS controls at both E12.5 (+1 DIV) and E13.5 (+1 DIV), the entire population of contralateral fibers projected in a direction normal to the midline. In cases of $\mathrm{Ch}^{\mathrm{ABC}}$, unfasciculated fibers that deviated from this normal direction were excluded and not represented in the histograms.

Pathway deviation by unfasciculated fibers reflects that $\mathrm{Ch}^{\mathrm{ABC}}$ acted to expose alternative cues that detract the late projections from the pioneer path. Matrix CS therefore restricts late projections to the path charted out by pioneer projections.

\section{Number of Dil-tracked fibers}

At E12.5 (+1 DIV) in PBS, 74\% (25/34) of initial projections toward the contralateral side extended as far as $600 \mu \mathrm{m}$. Only 10 or fewer extended beyond $600 \mu \mathrm{m}$ and numbers declined at a rate of 3 fibers per $100 \mu \mathrm{m}$. At $\mathrm{E} 12.5_{(+1 \mathrm{DIV})}$ in $\mathrm{Ch}^{\mathrm{ABC}}$, projections that extended as far as $200 \mu \mathrm{m}$ were increased by 2 to 3 times compared to the PBS control, totaling 60 fibers and declining at a rate of 2 fibers per $100 \mu \mathrm{m}$ to reach 30 fibers by 600 to $1,000 \mu \mathrm{m}$ Some 20 fibers crossed the midline and $<10$ projected for $350 \mu \mathrm{m}$ beyond the midline; the rate of decline across the floor plate $(1,000$ to $1,300 \mu \mathrm{m})$ was 5 fibers per $100 \mu \mathrm{m}$.

At E13.5 $5_{(+1}$ DIV) in PBS, the initial projections (around 60) persisted up to $1,100 \mu \mathrm{m}$ (approximately the midline). Thereafter, numbers declined at a rate of 5 fibers per $100 \mu \mathrm{m}$ up to $1,400 \mu \mathrm{m}$ and then at lower rates until they were at a barely detectable level at 2,100 $\mu \mathrm{m}$. In $\mathrm{Ch}^{\mathrm{ABC}}$, from about 70 fibers in the initial 200 to 300 $\mu \mathrm{m}$, new levels reaching about 90 were maintained up to $700 \mu \mathrm{m}$. Numbers dropped at a rate of 7 fibers per $100 \mu \mathrm{m}$ across the midline to $1,400 \mu \mathrm{m}$. Then gradually at a rate of 3 fibers per $100 \mu \mathrm{m}$, numbers reached 15 fibers and remained so within 1,900 to $2,100 \mu \mathrm{m}$ before further declining to the basal level at 2,600 nm. At both 


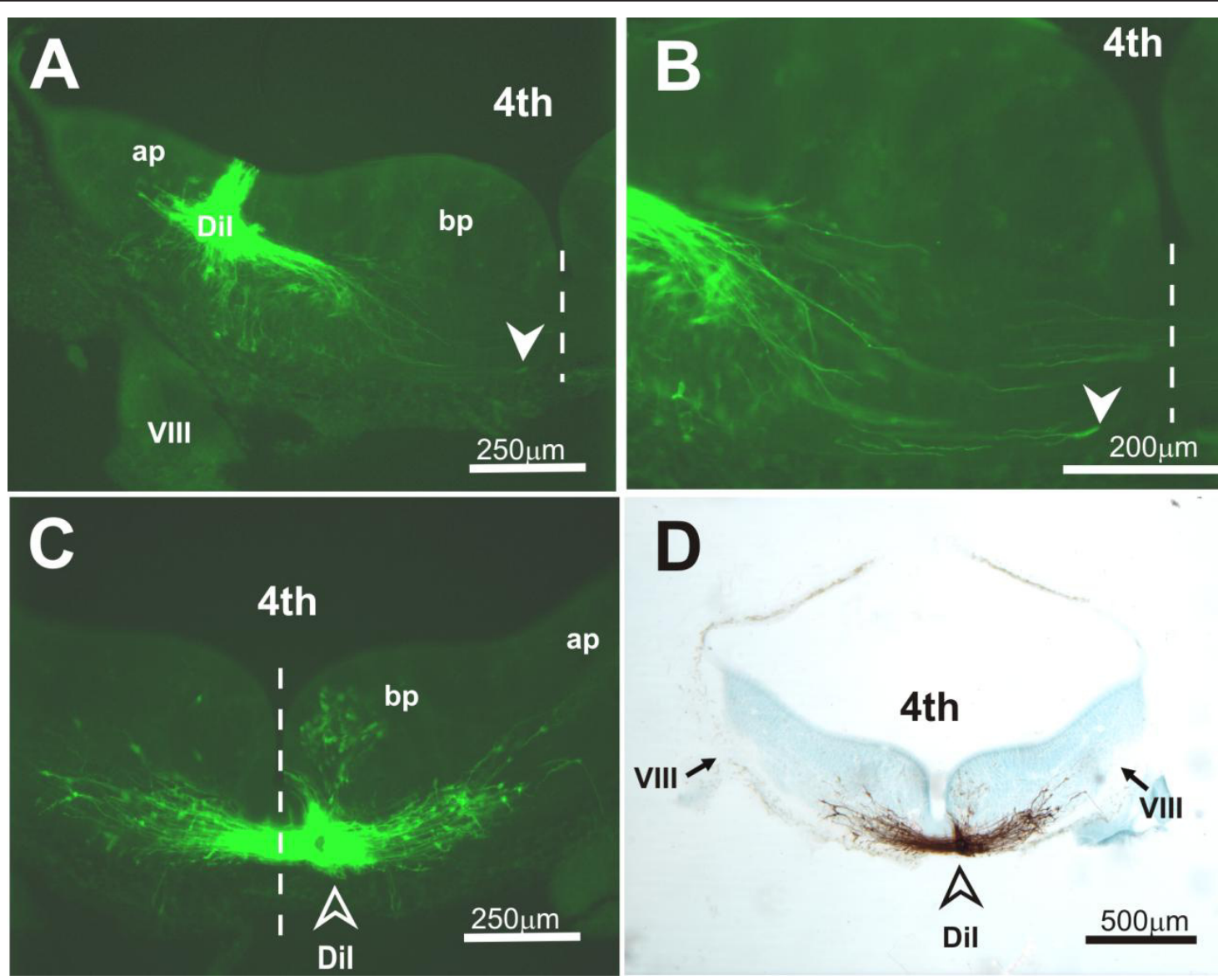

Figure 5 Preliminary experiments to track the course of labeled fibers following Dil injection into the indicated sites in the hindbrain (E13.5). (A,B) Transverse section of the hindbrain at the level of the VIIIth cranial nerve root (VIII) showing Dil applied at a site approximately $150 \mathrm{\mu m}$ into the alar plate and labeled projections coursing in a ventromedial direction towards the midline. Images were as viewed under epifluorescence microscopy with use of an FITC filter. Panel (B) is a magnified view of (A), showing growth cone-like terminals (solid arrowhead) of projection fibers approaching the midline. Dashed line denotes the midline. (C,D) Transverse section as in (A) but showing Dil applied into the floor plate (open arrowhead) for retrograde labeling of neurons. Images were as viewed under epifluorescence microscopy with use of an FITC filter (C), or after photoconversion of Dil labeling into a stable diaminobenzidine reaction product (D). The latter was counterstained with cresyl violet. Most cells that were so labeled are identifiable within the prospective area of the reticular formation; few, if any, labeled cells are observable in the area of the VN. Abbreviations: 4th, fourth ventricle; ap, alar plate; bp, basal plate; $c p$, cerebellar primordium; V, Vth cranial nerve root; VIII, VIIIth cranial nerve root; $r 2$ to $r 7$, rhombomeres 2 to 7 .

stages, the increased numbers on the ipsilateral side reinforce that depletion of matrix $\mathrm{CS}$ by $\mathrm{Ch}^{\mathrm{ABC}}$ activity removed limitations to fiber space such that late projections remain unfasciculated as they traverse the hindbrain matrix toward the contralateral side.

\section{Fasciculation of Dil-tracked fibers}

At E12.5 (+1 DIV) in PBS, 30 to $50 \%$ of projections within the initial $500 \mu \mathrm{m}$ were fasciculated and by 700 to 900 $\mu \mathrm{m}$, fibers were few and mainly unfasciculated. In $\mathrm{Ch}^{\mathrm{ABC}}$, a declining proportion (42 to $25 \%$ of fibers) within the initial $200 \mu \mathrm{m}$ was fasciculated and an increasing proportion was unfasciculated. From 300 to $700 \mu \mathrm{m}$, the proportion of fasciculated fibers remained low at 10 to $11 \%$. Fibers crossing the midline and projecting in the contralateral side were unfasciculated.
At E13.5 (+1 DIV) in PBS, 30 to $40 \%$ of projections remained fasciculated up to $800 \mu \mathrm{m}$. Across the midline till $1,400 \mu \mathrm{m}$, fasciculated fibers were maintained at $20 \%$ of projections but total fiber number declined. By 1,500 $\mu \mathrm{m}$, fibers were unfasciculated. Hardly any were detectable by $2,100 \mu \mathrm{m}$. In $\mathrm{Ch}^{\mathrm{ABC}}$, > 95\% of fibers on the ipsilateral side (within $900 \mu \mathrm{m}$ ) were unfacsiculated. Across the midline till 2,600 $\mu \mathrm{m}$, fasciculated fibers were minimal, if any. Digestion of matrix $\mathrm{CS}$ by $\mathrm{Ch}^{\mathrm{ABC}}$ therefore removes barriers that otherwise limit follower projections to fasciculate and to conform with the path of pioneer projections.

\section{Projection distance}

At E12.5 $5_{(+1}$ DIV) in PBS, the furthest projections were short of the midline by $150 \mu \mathrm{m}$. In $\mathrm{Ch}^{\mathrm{ABC}}$, the furthest 

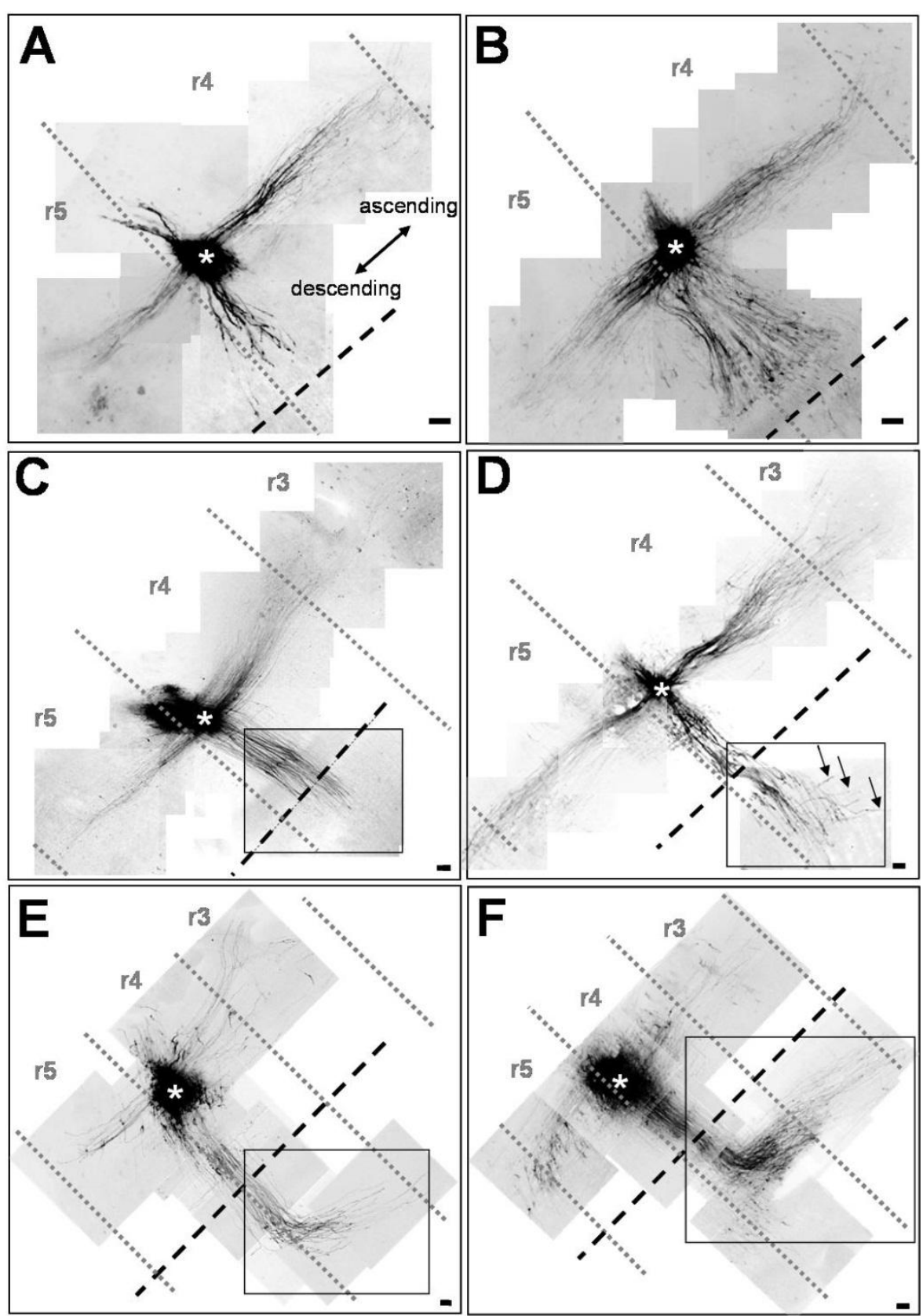

Figure 6 Gray-scale montages representing Dil-tracked projections from the VN neurons. (A,B) E12.5(+1 DIV) (C,D) E13.5(+1 DIV) (E,F) E14.5 (+1 DIV). after the injection of PBS (control) $(A, C, F)$ or $C^{A B C}$ (test) (B,D,F). (A) At E12.5 $5_{(+1}$ DIV in PBS, projections assumed fascicles as they advanced toward the midline. (B) At E12.5(+1 DIV in $\mathrm{Ch}^{\mathrm{ABC}}$, many projections were unfasciculated as they approached normal to the midline and a subpopulation crossed the midline. (C) At E13.5 $(+1$ DIV in PBS, projections were fasciculated as they approached and crossed the midline. (D) At E13.5(+1 DIV in $\mathrm{Ch}^{\mathrm{ABC}}$, pioneer projections advanced normal to the midline as fascicles and beyond towards the contralateral VN. Later projections traversed the enzyme-treated matrix as unfasciculated fibers and deviated from the course of the pioneers (arrows). (E) At E14.5(+1 DIv in PBS, projections advanced as fascicles to the contralateral VN and then turned in the anterior direction. (F) At E14.5(+1 DIV in Ch ${ }^{\mathrm{ABC}}$, commissural projections were partly fasciculated and partly not but mostly unfasciculated as they made the anterior turn. Zoomed-in views of boxed areas are shown in Figure 7. Asterisks indicate the site of Dil injection, dotted lines the rhombomere boundaries, and dashed lines the midline. Abbreviations: r, rhombomere; Scale bar: $100 \mu \mathrm{m}$. 


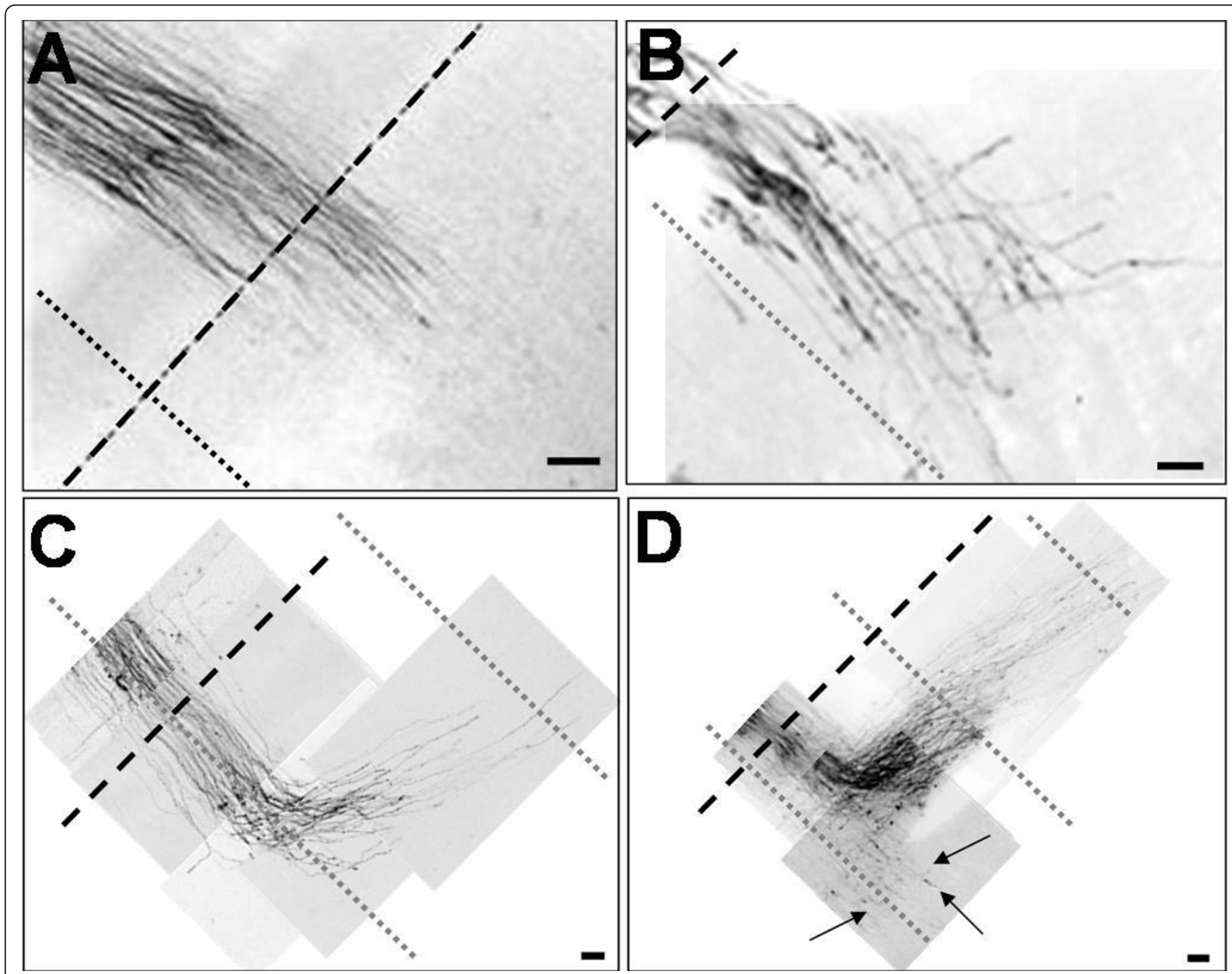

Figure 7 Zoomed-in views of boxed areas in Figure 6 showing fibers at midline crossing and at the contralateral site. (A,B) E13.5(+1 DIV); $(C, D) E 14.5_{(+1} \mathrm{DIN} ;(A, C)$ control treatment with PBS; $(B, D)$ test treatment with $C^{A B C}$. At E13.5 in PBS, fibers advanced as fascicles normal to the the midline. At E13.5 (+1 DIV in $C h^{A B C}$, a subpopulation of unfasciculated fibers projected normal to the midline and crossed to the contralateral side but others deviated from the normal trajectories. At E14.5 (+1 DIV) in $\mathrm{Ch}^{\mathrm{ABC}}$, most fibers made the anterior turn but some unfasciculated fibers (arrows) failed to make the turn.. The dashed line indicates the midline, and dotted lines the rhombomerre boundaries. Scale bar: $100 \mu \mathrm{m}$.

projections were $350 \mu \mathrm{m}$ beyond the midline. At E13.5 (+1 DIV) in PBS, projections reached as far as $2,100 \mu \mathrm{m}$ into the contralateral side. In $\mathrm{Ch}^{\mathrm{ABC}}$, projections reached further into the contralateral side, reaching $2,600 \mu \mathrm{m}$. Digestion of matrix CS by $\mathrm{Ch}^{\mathrm{ABC}}$ therefore removes spatial limitations and promotes growth and advancement of pioneers to regions even beyond the contralateral side.

At E14.5 ${ }_{(+1}$ DIV), in both PBS controls and $\mathrm{Ch}^{\mathrm{ABC}}$-treated embryos, the distance between the DiI injection site and the midline was apparently shorter than those in E12.5 (+1 DIV) and E13.5 (+1 DIV) embryos (Figure 6). This was related to a decrease in the area of the ventricular surface of the neural tube with development and an increase in the thickness of the neural tube due possibly to proliferation of neuroepithelial cells and matrix deposition by neuroblasts. Proper flat-mounts of embryonic hindbrains could hardly be prepared. As a result, fiber projections were at angles inclined from the horizontal but viewed as if flat on the page.

\section{Discussion}

In the present study, our results show that CS moieties in the rat hindbrain matrix (E12.5 $5_{+1}$ DIV) and E13.5 $5_{(+1}$ DIV) ) are important for controlling commissural projection of VN neurons at a time when few, if any, fiber tracts have charted out their course in the early hindbrain.

During the development of the hindbrain, segmentation of the neuroepithelium into rhombomeres is important in laying out the framework for correct neuronal patterning [2]. Projection of VN commissures during 


\section{Figure 8}

A

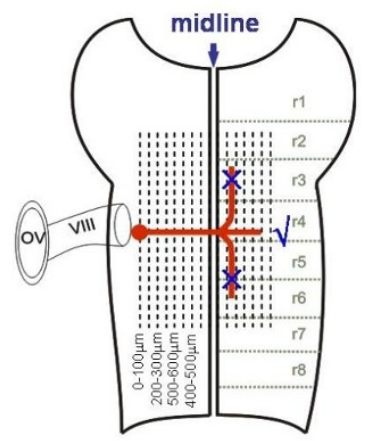

C

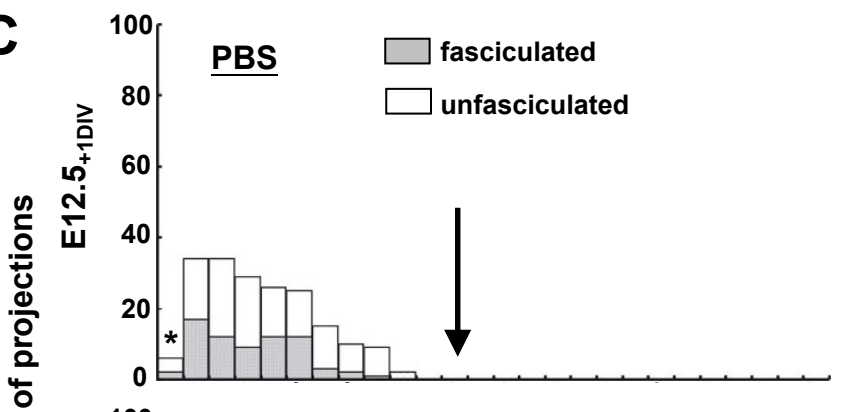

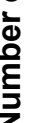

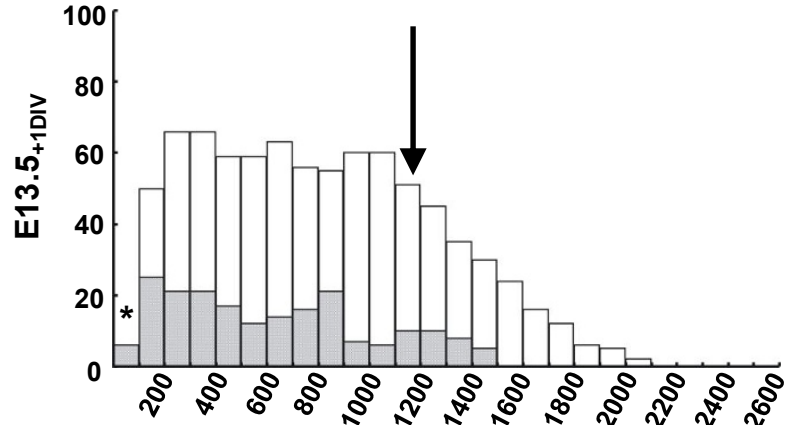

Distance from the point of injection $(\mu \mathrm{m})$
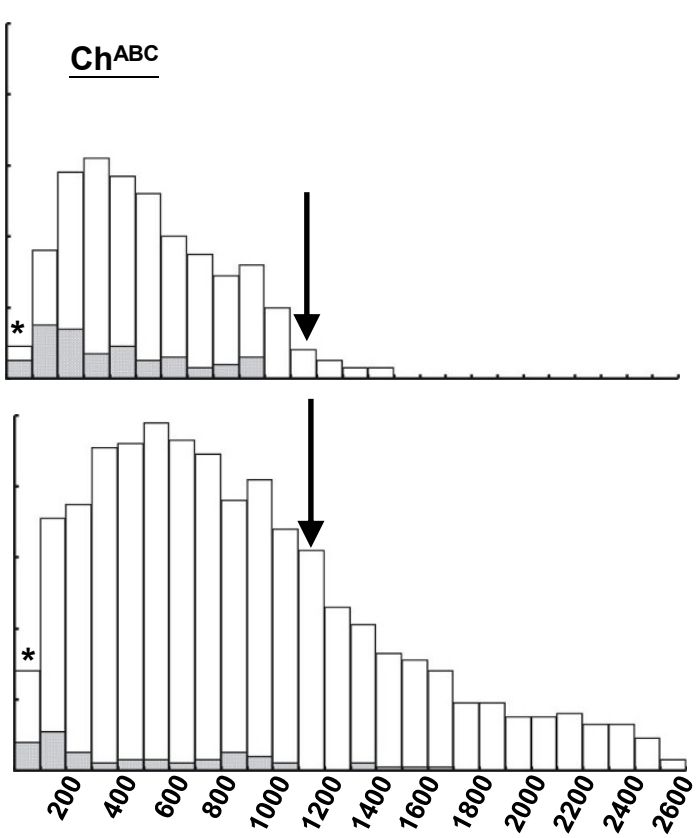

Figure 8 Quantification of Dil-tracked commissural projections of the VN. (A) Schematic diagram showing overlay of longituinal gridlines against Dil-tracked fiber projections (red) of the hindbrain flat-mounts. The injection site was set as '0' and projections to the right (contralateral) were counted. (B) Image of fasciculated fibers (thick arrows) mixed with unfasciculated fibers (thin arrows). (C) Histograms of fasciculated and unfasciculated projections against the distance from the Dil injection site in hindbrains treated with PBS (left panels) and with Ch ${ }^{A B C}$ (right panels). Data are representative of five individual sets of experiments at E12.5(+1 DIV and E13.5(+1 DIV). The downward pointing arrow indicates the position of the midline. Asterisks denote regions within $100 \mu \mathrm{m}$ of the DI injection site where the intensity of dye precluded accuracy of fibre counts.

this period when few fiber tracts exist and the coincidental abundance of CSPGs in the hindbrain matrix suggest a role for this molecule in regulating the commissural projection. Studies of the embryonic chick brain showed CSPG accumulation in the extracellular matrix of rhombomere boundaries $[17,18]$. The CS moiety has been considered important in restricting cell clusters and preventing them from intermingling with clusters of different cell lineages and thus in maintaining identities of cell clusters in the hindbrain. With the use of immunostaining for the CS-56 epitope and the 2B6 stub epitope following $\mathrm{Ch}^{\mathrm{ABC}}$ treatment of the hindbrain matrix, we showed that the CS moieties are localized in the extracellular matrix of rhombomeric segments as well as the boundaries of rhombomeres (Figure 3A,E). Cells and their projections can traverse this CS-rich region in the rhombomeres. So, does the restrictive role of CS in rhombomeres apply in such circumstances?

The CS moiety has been implicated in the control of neurite growth and extension. Culture of chick retinal ganglion cells on nitrocellulose filters that have been implanted in a lesioned cerebral cortex to capture 
CSPGs of the glial scar showed that treatment of the filter with $\mathrm{Ch}^{\mathrm{ABC}}$ resulted in cultures bearing longer neurites [19]. Treatment of chiasmatic brain slice cultures (E13 to E15, mouse) with $\mathrm{Ch}^{\mathrm{ABC}}$ resulted in misrouting of retinal ganglion cell projections at the optic chiasma [20]. In the present study, we showed that treatment of hindbrain matrix with $\mathrm{Ch}^{\mathrm{ABC}}$ in 1-day cultures of rat embryos sped up projection along the commissural route toward the contralateral VN. This effect was evident in both E12.5 (+1 DIV) and E13.5 (+1 DIV) embryos - in the former, projections reached further by $800 \mu \mathrm{m}$ along the commissural route, and in the latter, projections ended up in regions beyond the contralateral VN (Figure 8). Our results suggest that CS moieties prevailing in the early hindbrain matrix play an axon-restrictive role in controlling the speed of projection of the $\mathrm{VN}$ commissures such that the terminals can recognize the targets on arrival.

In this work, we found that $\mathrm{VN}$ commissural fibers were less fasciculated in hindbrains that had been treated with $\mathrm{Ch}^{\mathrm{ABC}}$ than those of controls treated with PBS. For assessment of the extent of fasciculation of the VN commissural fibers in 100- $\mu \mathrm{m}$ steps across the hindbrain, we chose fiber diameters of $>5 \mu \mathrm{m}$ as an arbitrary indication of fasciculation and those $\leq 5 \mu \mathrm{m}$ as an indication of non-fasciculation. This cutoff makes it possible for exhaustive assessment of all DiI-tracked fibers at the light microscopic level. Assessment of fibers of $\leq 5$ $\mu \mathrm{m}$ in close-up view revealed that these included three to five single projections that, at times, were separate from each other and, at other times, remained indiscernible. To decipher these would require viewing at the electron microscopic level. This latter approach can only reveal a small portion of the examined area each time and is impractical for assessment of all the labeled VN commissures. Our observation of increase in unfasciculated fibers with $\mathrm{Ch}^{\mathrm{ABC}}$ treatment of the hindbrain suggests that axon-restrictive CS moieties in the hindbrain matrix induced the late outgrowths or follower projections to join the track of pioneers and thus to fasciculate with each other.

Earlier studies considered CSPG as an entity and did not attempt to distinguish between roles of the CS moiety and those of the core proteins. Thus, such CSPGs as neurocan and phosphacan were found to mediate axonal fasciculation during development of the hippocampal circuitry in vivo [21]. In cultures of hippocampal neurons, dorsal root ganglia or habenula nucleus neurons, neurite extension into a CSPG substratum exhibited fasciculation as well [21-23]. These provide evidence for axonal fasciculation as a means to modulate the ability of the growth cone to navigate through restrictive environments or regulate axonal pathfinding during circuit formation.
Our results provide an in vivo correlate to the in vitro findings of [24] that the CS moieties of neural proteoglycans such as neurocan and phosphacan have roles in the modulation of neuronal adhesion and neurite growth by binding to neural cell adhesion molecules like neuron-glia cell adhesion molecule (Ng-CAM) and neural cell adhesion molecule (N-CAM). Treatment of the hindbrain matrix with $\mathrm{Ch}^{\mathrm{ABC}}$ when the projecting fibers are in the growing mode not only diminished matrix restriction of cues and guideposts, but can likely interfere with the modulation of molecular interactions involving the CAMs at close axonal contacts. The CAMs on neurons have sites for homophilic binding with cell attached CAMs [25-27], and other sites for binding with neurocan and phosphacan, both the glycosylated form and the $\mathrm{Ch}^{\mathrm{ABC}}$-treated counterpart $[28,29]$. Direct binding of neurons with the native or $\mathrm{Ch}^{\mathrm{ABC}}$ treated neurocan and phosphacan via $\mathrm{Ng}$-CAM and $\mathrm{N}$ CAM was demonstrated $[28,29]$. We reason that the CS moieties are uniquely poised to fine-tune the balance between adhesion and anti-adhesion for growing axons to navigate along pre-existing axonal trajectories.

The strong CS-56 immunopositivity remaining at the ventricular surface despite the proximity to the infused $\mathrm{Ch}^{\mathrm{ABC}}$ suggests limited access of the enzyme to CS moieties on the ventricular surface. It is likely that the CSPGs were protected from enzymatic digestion via interaction with other extracellular matrix molecules. In one of the other experiments in our lab, we have shown that the release of semaphorin3A, which binds to CS moieties in the central nervous system [30], could only be achieved when the samples were treated with both $\mathrm{Ch}^{\mathrm{ABC}}$ and heparitinases, but not with $\mathrm{Ch}^{\mathrm{ABC}}$ alone (unpublished data). These results support that by interaction with other extracellular matrix molecules, the CS moiety is protected from the action of $\mathrm{Ch}^{\mathrm{ABC}}$ and presents as residual immunoreactivity to CS-56.

There is a concern that the differences we observed in axonal trajectories with and without $\mathrm{Ch}^{\mathrm{ABC}}$ treatment is due to increased apoptosis in the embryos, in particular the higher mortality rate among E14.5 embryos in culture (Figure 2). Given that CSPGs bind various chemokines and growth factors (personal communication), $\mathrm{Ch}^{\mathrm{ABC}}$ cleavage of the CS moiety may result in loss of these factors and therefore increased incidence of cell death. In order to verify that the results we reported are due to $\mathrm{Ch}^{\mathrm{ABC}}$ cleavage of the CS moiety but not other cellular processes, such as apoptosis, we monitored the development of the embryos by their heartbeat and their growth in size after the ex vivo culture. We did not observe any differences in size between the PBS- and $\mathrm{Ch}^{\mathrm{ABC}}$-treated embryos. Embryos with slow heartbeats or reduced size were discarded at the end of the culture and were not included for DiI tracking of commissural 
projections from the VN. Moreover, cross-sections of these embryos have been immunostained with NF165 and results showed that the numbers of neurites were similar in both cases (results not shown). Admittedly, these results cannot provide definitive proof that all subpopulations of neurons are equally protected. More experiments have to be performed to reveal the contribution of CSPGs to the survival of subpopulations of neurons.

CS is a well known inhibitory molecule in the nervous system. The high abundance of CSPGs in the glial scar that forms after nervous tissue injury suggests their role in limiting regeneration [31,32]. With the removal of CS by $\mathrm{Ch}^{\mathrm{ABC}}$ treatment of the glial scar, axonal transgression of the scar was observed [33-39]. This raises the question of how the projections negotiate their way through the CS-rich environment. With rat dorsal root ganglia in culture on aggrecan-laminin substrata, inhibition of neurite extension by the CS moiety of aggrecan was attributed to suppression of integrin signaling and that the inhibition could be reversed by integrin activation [40]. Alternatively, chick dorsal root ganglia culture treated with versican V0/V1 forms revealed concentration-dependent neurite responses that ranged from rapid retraction and deflection to defasciculation and growth arrest [41]. Our work is the first to demonstrate the role of CS moieties in the early hindbrain matrix in controlling the pattern of projection of $\mathrm{VN}$ commissures for timely arrival at the contralateral target. Further study on various CS isoforms may give new insights into mechanisms by which the CS moiety can fine-tune adhesion versus anti-adhesion signaling at the growth terminal to allow navigation along axonal trajectories in early hindbrain development.

\section{Abbreviations}

$\mathrm{Ch}^{\mathrm{ABC}}$ : chondroitinase $\mathrm{ABC}$; $\mathrm{CAM}$ : cell adhesion molecule; CS: chondroitin sulfate; CSPG: chondroitin sulfate proteoglycan; Dulbecco's modified Eagle's Medium; E: embryonic day; N-CAM: Neural cell adhesion molecule; Ng-CAM: neuron-glia cell adhesion molecule; PBS: phosphate-buffered saline; VN: vestibular nucleus.

\section{Acknowledgements}

This work was supported by a GRF research grant from the Hong Kong Research Grants Council to YSC and DKYS (HKU 7670/06M). We thank Alice YY Lui, Kimmy FL Tsang and Simon CM Chan of The University of Hong Kong for their excellent technical support in this work.

\footnotetext{
Author details

'Department of Biochemistry, LKS Faculty of Medicine, The University of Hong Kong, Sassoon Road, Hong Kong, China. ${ }^{2}$ Cambridge Centre for Brain Repair, Cambridge University, Forvie Site, Robinson Way, Cambridge CB2 OPY, UK. ${ }^{3}$ Department of Physiology, LKS Faculty of Medicine, The University of Hong Kong, Sassoon Road, Hong Kong, China. ${ }^{4}$ Department of Anatomy, Histology and Embryology, The Fourth Military Medical University, Xi'an, China. ${ }^{5}$ Research Centre of Heart, Brain, Hormone and Healthy Aging, LKS Faculty of Medicine, The University of Hong Kong, Sassoon Road, Hong Kong, China.
}

\section{Authors' contributions}

JCFK performed chondroitinase treatment of rat embryos in culture, analyzed mmunohistochemical results and Dil-tracked fiber projections, and drafted the manuscript. YLY and WKL carried out embryo culture studies, including Dil tracking of commissural projections in the embryonic hindbrain. FXZ performed initial fiber-tracking experiments that standardized the Dil application site in the embryonic hindbrain. JWF participated in the conception of the study and interpretation of chondroitinase activity in the hindbrain. YSC participated in planning of the experiments, analysis and interpretation of fiber projections, and the writing of the manuscript. DKYS conceived of the study, designed and coordinated the experiments, and wrote the manuscript. All authors read and approved the final manuscript.

\section{Competing interests}

The authors declare that they have no competing interests.

Received: 5 June 2011 Accepted: 3 February 2012

Published: 3 February 2012

\section{References}

1. Lumsden A, Keynes R: Segmental patterns of neuronal development in the chick hindbrain. Nature 1989, 337:424-428.

2. Lumsden A: The cellular basis of segmentation in the developing hindbrain. Trends Neurosci 1990, 13:329-335.

3. Clarke JDW, Lumsden A: Segmental repetition of neuronal phenotype sets in the chick embryo hindbrain. Development 1993, 118:151-162.

4. Nieto MA, Bradley LC, Wilkinson DG: Conserved segmental expression of Krox-20 in the vertebrate hindbrain and its relationship to lineage restriction. Development 1991, Supplement 2:59-62.

5. Sham MH, Vesque $C$, Nonchev $S$, Marshall $H$, Frain M, Gupta RD, Whiting J, Wilkinson D, Charnay P, Krumlauf R: The zinc finger gene Krox20 regulates HoxB2 (Hox2.8) during hindbrain segmentation. Cell 1993, 72:183-196.

6. Trainor PA, Krumlauf R: Patterning the cranial neural crest: hindbrain segmentation and Hox gene plasticity. Nat Rev Neurosci 2000, 1:116-124.

7. Altman J, Bayer SA: Development of the brain stem in the rat. III. Thymidine-radiographic study of the time of origin of neurons of the vestibular and auditory nuclei of the upper medulla. J Comp Neurol 1980, 194:877-904

8. Maklad A, Fritzsch B: Development of vestibular afferent projections into the hindbrain and their central targets. Brain Res Bull 2003, 60:497-510.

9. Auclair F, Marchand R, Glover JC: Regional patterning of reticulospinal and vestibulospinal neurons in the hindbrain of mouse and rat embryos. J Comp Neurol 1999, 411:288-300.

10. Pasqualetti M, Diaz C, Renaud J-S, Riuli FM, Glover JC: Fate-mapping the mammalian hindbrain: segmental origins of vestibular projection neurons assessed using rhombomere-specific Hoxa2 enhancer elements in the mouse embryo. J Neurosci 2007, 27:670-9681.

11. Mellitzer $G, X u Q$, Wilkinson DG: Eph receptors and ephrins restrict cell intermingling and communication. Nature 1999, 400:77-81.

12. Xu Q, Mellitzer $G$, Robinson V, Wilkinson DG: In vivo cell sorting in complementary segmental domains mediated by Eph receptors and ephrins. Nature 1999, 399:267-271.

13. Xu Q, Mellitzer G, Wilkinson DG: Roles of Eph receptors and ephrins in segmental patterning. Phil Trans R Soc Lond B 2000, 355:993-1002.

14. Kitagawa H, Ujikawa M, Tsutsumi K, Tamura J, Neumann KW, Ogawa T, Sugahara K: Characterisation of serum $\beta$-glucuronyltransferase involved in chondroitin sulfate biosynthesis. Glycobiology 1997, 7:905-911.

15. New DAT: Whole-embryo culture and the study of mammalian embryos during organogenesis. Biol Rev 1978, 53:81-122.

16. Fritzsch B, Muirhead KA, Feng F, Gray BD, Ohlsson-Wilhelm BM: Diffusion and imaging properties of three new lipophilic tracers, NeuroVueTM Maroon, NeuroVueTM Red and NeuroVue TM Green and their use for double and triple labeling of neuronal profile. Brain Res Bull 2005, 66:249-258.

17. Heyman I, Faissner A, Lumsden A: Cell and matrix specializations of rhombomere boundaries. Dev Dyn 1995, 204:301-315.

18. Golding JP, Tidcombe H, Tsoni S, Gassmann M: Chondroitin sulphatebinding molecules may pattern central projections of sensory axons within the cranial mesenchyme of the developing mouse. Dev Biol 1999, 216:85-97. 
19. McKeon RJ, Hoke A, Silver J: Injury-induced proteoglycans inhibit the potential for laminin-mediated axon growth on astrocytic scars. Exp Neurol 1995, 136:32-42.

20. Chung KY, Taylor JSH, Shum DKY, Chan SO: Axon routing at the optic chiasm after enzymatic removal of chondroitin sulfate in mouse embryos. Development 2000, 127:2673-2683.

21. Wilson MT, Snow DM: Chondroitin sulfate proteoglycan expression pattern in hippocampal development: potential regulation of axon tract formation. J Comp Neurol 2000, 424:532-546.

22. Snow DM, Smith JD, Cunningham AT, MCFarlin J, Goshorn EC: Neurite elongation on chondroitin sulfate proteoglycans is characterized by axonal fasciculation. Exp Neurol 2003, 182:310-321.

23. Kantor DB, Chivatakarn O, Peer KL, Oster SF, Inatani M, Hansen MJ, Flanagan JG, Yamaguchi Y, Sretavan DW, Giger RJ, Kolodkin AL: Semaphorin $5 \mathrm{~A}$ is a bifunctional axon guidance cue regulated by heparan and chondroitin sulfate proteoglycans. Neuron 2004, 44:961-975.

24. Friedlander DR, Milev P, Karthikeyan L, Margolis RK, Margolis RU, Grumet M: The neuronal chondroitin sulfate proteoglycan neurocan binds to the neural cell adhesion molecules Ng-CAM/L1/NILE and N-CAM, and inhibits neuronal adhesion and neurite outgrowth. J Cell Biol 1994, 125:669-680.

25. Grumet M, Edelman GM: Neuron-glia cell adhesion molecule interacts with neurons and astroglia via different binding mechanisms. J Cell Biol 1998, 106:487-503

26. Acheson A, Sunshine $\mathrm{L}$, Rutihauser U: NCAM polysialic acid can regulate both cell-cell and cell-substrate interactions. J Cell Biol 1991, 114:143-153.

27. Tang J, Rutihauser U, Landmesser L: Polysialic acid regulates growth cone behavior during sorting of motor axons in the plexus region. Neuron 1994, 13:405-414.

28. Grumet M, Flaccus A, Margolis RU: Functional characterization of chondroitin sulfate proteoglycans of brain: interactions with neurons and neural cell adhesion molecules. J Cell Biol 1993, 120:815-824.

29. Milev P, Friedlander DR, Sakurai T, Karthikeyan L, Flad M, Margolis RK, Grumet M, Margolis RU: Interactions of the chondroitin sulfate proteoglycan phosphacan, the extracellular domain of a receptor-type protein tyrosine phosphatase, with neurons, glia, and neural cell adhesion molecules. J Cell Biol 1994, 127:1703-1715.

30. De Wit J, De Winter F, Klooster J, Verhaagen J: Semaphorin 3A displays a punctate distribution on the surface of neuronal cells and interacts with proteoglycans in the extracellular matrix. Mol Cell Neurosci 2005, 29:40-55.

31. McKeon RJ, Schreiber RC, Rudge JS, Silver J: Reduction of neurite outgrowth in a model of glial scarring following CNS injury is correlated with the expression of inhibitory molecules on reactive astrocytes. $J$ Neurosci 1991, 11:3398-3411.

32. Asher RA, Morgenstern DA, Moon LD, Fawcett JW: Chondroitin sulphate proteoglycans: inhibitory components of the glial scar. Prog Brain Res 2001, 132:611-619.

33. Dou CH, Levine JM: Differential effects of glycosaminoglycans on neurite growth on laminin and L1 substrates. J Neurosci 1995, 15:8053-8066.

34. Zuo J, Neubauer D, Dyess K, Ferguson TA, Muir D: Degradation of chondroitin sulfate proteoglycan enhances the neurite-promoting potential of spinal cord tissue. Exp Neurol 1998, 154:654-662.

35. Zuo J, Neubauer D, Graham J, Krekoski CA, Ferguson TA, Muir D: Regeneration of axons after nerve transection repair is enhanced by degradation of chondroitin sulfate proteoglycan. Exp Neurol 2002, 176:221-228.

36. Smith-Thomas LC, Fok-Seang J, Stevens J, Du JS, Muir E, Faissner A, Geller HM, Rogers JH, Fawcett JW: An inhibitor of neurite outgrowth produced by astrocytes. J Cell Sci 1994, 107:1687-1695.

37. Smith-Thomas LC, Stevens J, Fok-Seang J, Faissner A, Rogers JH, Fawcett JW: Increased axon regeneration in astrocytes grown in the presence of proteoglycan synthesis inhibitors. J Cell Sci 1995, 108:1307-1315.

38. Bradbury EJ, Moon LD, Popat RJ, King VR, Bennett GS, Patel PN, Fawcett JW McMahon SB: Chonrotinase $A B C$ promotes functional recovery after spinal cord injury. Nature 2002, 416:636-640.

39. Chau CH, Shum DKY, Li H, Pei J, Lui YY, Wirthlin L, Chan YS, Xu XM: Chondroitinase $A B C$ enhances axonal regrowth through Schwann cellseeded guidance channels after spinal cord injury. FASEB J 2004, 18:194-196.
40. Tan CL, Kwok JC, Patani R, ffrench-Constant C, Chandran S, Fawcett JW: Integrin activation promotes axon growth on inhibitory chondroitin sulfate proteoglycans by enhancing integrin signaling. J Neurosci 2011, 31:6289-6295.

41. Dutt S, Cassoly E, Dours-Zimmermann MT, Matasci M, Stoeckli ET, Zimmermann DR: Versican V0 and V1 direct the growth of peripheral axons in the developing chick hindlimb. J Neurosci 2011, 31:5262-5270.

doi:10.1186/1749-8104-7-6

Cite this article as: Kwok et al:: Chondroitin sulfates in the developing rat hindbrain confine commissural projections of vestibular nuclear neurons. Neural Development 2012 7:6.

\section{Submit your next manuscript to BioMed Central and take full advantage of:}

- Convenient online submission

- Thorough peer review

- No space constraints or color figure charges

- Immediate publication on acceptance

- Inclusion in PubMed, CAS, Scopus and Google Scholar

- Research which is freely available for redistribution

Submit your manuscript at www.biomedcentral.com/submit
C) Biomed Central 